\title{
Diagnóstico clínico-radiológico de neumonía por COVID-19 (SARS-CoV-2) en el Hospital Ángeles Lomas
}

\author{
Clinical-radiological diagnosis of pneumonia by COVID-19 \\ (SARS-CoV-2) at Hospital Ángeles Lomas
}

\author{
Horacio Lozano Zalce, * Ángel César Chávez Alanís, * Ignacio Gustavo Álvarez Valero, ${ }^{\neq}$ \\ Ximena Ochoa Morales, ${ }^{\ddagger}$ Raymundo Rodríguez Sandoval, \$ Pilar Escamilla Llano॥
}

\section{Resumen}

El propósito de este artículo es compartir la experiencia de un hospital privado de la zona conurbada de la Ciudad de México, cuyo abordaje diagnóstico se realizó en pacientes con sospecha de neumonía por COVID-19. Los Departamentos de Urgencias e Imagenología trabajaron de manera coordinada y estructurada, apoyados por el laboratorio clínico y por el de biología molecular. La relativa facilidad de nuestro hospital en la realización de la prueba diagnóstica de elección (rt-PCR) y la de contar con equipo de tomografía computarizada, así como el tipo de población atendida, hicieron que muy rápido se lograra la identificación de los pacientes con esta enfermedad. De esta manera, se describe el abordaje clínico, laboratorial y radiológico, así como los hallazgos de imagen típicos, y su comparación con lo reportado en la literatura.

Palabras clave: COVID-19, imagen de tórax para COVID-19, neumonía por SARS-CoV-2.

\section{INTRODUCCIÓN}

En diciembre de 2019, en la ciudad de Wuhan, China, se iniciaron los primeros reportes de un cuadro clínico que se caracterizaba por una infección aguda y severa de las vías aéreas inferiores, cuyo reconocimiento del agente causal resultó un coronavirus. ${ }^{1}$ La enfermedad fue designada como enfermedad por coronavirus de 2019 (abreviado el virus como SARS-CoV-2 y la enfermedad como COVID-19). Su velocidad de propagación y la contagiosidad inherente al virus hizo que en pocas semanas esta infección se hubiera

\section{Abstract}

The purpose of this article is to share the experience of a private Hospital in the metropolitan area of Mexico City, in the diagnostic approach of patients with suspected COVID-19 pneumonia. The Emergency and Imaging Departments worked in a coordinated and structured manner, supported by the Clinical and Molecular Biology Laboratory. The relative facility of our hospital in carrying out the diagnostic test of choice (rt-PCR), as well as the type of population served and the access to computed tomography equipment, made very fast and easy the diagnosis of patients with this illness. The clinical, laboratory and radiological approach is described, as well as the typical imaging findings and their comparison with that reported in the literature.

Keywords: COVID-19, chest CT for COVID-19, SARS-CoV-2 pneumoniae.

diseminado hacia los países asiáticos y, posteriormente, a Europa y al resto del mundo.

Existen otros síndromes respiratorios agudos que ya se han presentado en diferentes países relacionados y secundarios a otras especies de coronavirus; los ejemplos más notables son el SARS (por sus siglas en inglés: severe acute respiratory syndrome) y el MERS (por sus siglas en inglés: Middle East respiratory syndrome). Afortunadamente, el SARS (de moderada contagiosidad y elevada letalidad) se autolimitó, no sin antes haber dejado una gran cantidad de defunciones (8,422 enfermos y 916 muertos); ${ }^{2}$ se sabe

\footnotetext{
* Departamento de Imagenología.

* Servicio de Urgencias.

$\S$ Coordinador del Comité de Infecciones.

- Biología Molecular.
}

Hospital Ángeles Lomas. Ciudad de México, México.
Correspondencia:

Horacio Lozano Zalce

Correo electrónico: hlozanozalce@gmail.com

Aceptado: 08-04-2020.

www.medigraphic.com/actamedica 
que el último caso reportado fue en 2003. El MERS inició en 2014 en un paciente con neumonía y falla renal aguda: a partir de ahí, se identificaron 2,492 casos con 858 defunciones, ${ }^{3}$ y no fue sino hasta el año pasado que se reportó el último caso.

En el caso de COVID-19, la Organización Mundial de la Salud alertó al mundo sobre esta nueva epidemia, y el 30 de enero de 2020 lo declaró como una emergencia sanitaria global. Para mediados de febrero ya se habían documentado casos en 24 países. El 27 de febrero se reportó el primer caso en México (en el Instituto Nacional de Enfermedades Respiratorias), y paulatinamente, se fueron presentando más casos aislados en diferentes estados del nuestro país (la mayoría tenía como antecedente haber estado en un convención en la ciudad de Bérgamo, Italia). Para el día 6 de marzo, ya había seis casos, incluyendo el primer paciente que diagnosticamos en nuestro hospital (con prueba de PCR positiva confirmada). Hasta el día de hoy (9 de mayo), según cifras oficiales, en nuestro país, hay 31,522 casos positivos para COVID-19 con 3,160 defunciones (10\%).

\section{MATERIAL Y MÉTODOS}

En nuestra experiencia, al inicio, la identificación de los pacientes fue relativamente sencilla, ya que prácticamente todos los casos fueron "importados", es decir, tenían manifestaciones clínicas sugerentes y antecedentes de viaje al extranjero (particularmente a Italia, a España y a Estados Unidos).

El Servicio de Urgencias desarrolló (desde el 15 de enero de 2020) el "Protocolo de acción frente a casos sospechosos o probable por coronavirus 2019-nCov (SARS CoV-2)", en el cual se definió como "caso sospechoso" a cualquier paciente que había cursado con fiebre, enfermedad res- piratoria aguda (particularmente, con tos seca) y algún antecedente de viaje hacia países con casos confirmados dentro de 14 días previos al inicio de síntomas o había tenido contacto directamente con casos confirmados.

Los pacientes sospechosos fueron sometidos a una revisión clínica en la que se incluyeron la toma de signos vitales, una exploración torácica habitual y medidas de saturación de oxígeno mediante un oxímetro de pulso. El personal de salud empleó para ello una bata impermeable de manga larga, guantes no estériles, lentes de protección y mascarilla (cubrebocas) de tipo N95.

Se clasificó la enfermedad como leve, moderada y grave, considerando lo siguiente: leve y moderada en pacientes menores de 60 años y sin comorbilidades de importancia; moderada, con comorbilidades significativas, y los casos severos se definieron cuando se identificó una saturación de oxígeno $<90 \%$ y/o sospecha clínica de neumonía.

En todos los casos, se sometió al paciente a la recolección de muestras de secreciones a través de hisopado de orofaringe y de rinofaringe para la búsqueda del virus a través de la técnica rt-PCR (por sus siglas en inglés: reverse transcription-polymerase chain reaction).

En los casos considerados como moderados con factores de riesgo o casos severos, se interconsultó de inmediato con el Departamento de Neumología y se realizó una tomografía computarizada (TC) simple de alta resolución; la realización de una radiografía de tórax no fue considerada como una herramienta de inicio, ya que los hallazgos típicos iniciales son únicamente visibles en la TC.

El 22 de febrero de 2020 se realizó la primera prueba en un paciente sospechoso (la cual resultó negativa), y fue hasta el 4 de marzo de 2020 cuando se tuvo ya el primer caso con cuadro clínico, antecedente epidemiológico y prueba de rt-PCR positivos (la prueba se reportó validada por el INDRE el 6 de marzo).

Tabla 1: Descripción de los hallazgos en TC en la literatura mundial y nuestra experiencia.

Hallazgos por tomografía computarizada

Opacidades "vidrio despulido" (ground-glass)

Consolidación

Patrón en "empedrado" (crazy- paving)

Opacidades lineales

Cavitación

Nódulos no calcificados

Derrame pleural

Adenopatías

Distribución bilateral

Distribución periférica
Frecuencias de alteraciones informadas
Frecuencia de alteraciones encontradas en esta serie 


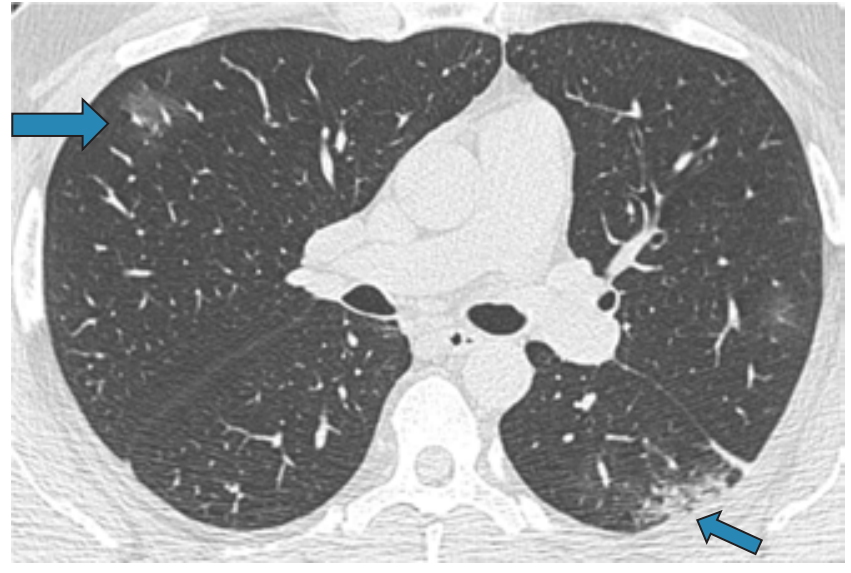

Figura 1: "Vidrio despulido" bilateral. Las flechas señalan las áreas afectadas con un incremento en la atenuación. Nótese que no se oscurecen las estructuras vasculares subyacentes.

Desde el 4 de marzo hasta el 10 de abril de 2020, se realizaron 880 pruebas (en pacientes que acudieron al Servicio de Urgencias), considerando que se hicieron muchos más hisopados en pacientes que fueron vistos por consulta externa, así como pruebas de otros muchos hospitales, incluyendo a los 25 de la red de Grupo Ángeles Servicios de Salud.

\section{RESULTADOS}

De esas 880 pruebas, 228 resultaron positivas para COVID-19, esto es, el 26\% del total de pacientes; dentro de esta misma población, se efectuaron 108 tomografías computarizadas por posibles casos de enfermedad moderada o severa. La edad promedio fue de 45 años (intervalo de 10 a 81 años), los días de síntomas fueron en promedio 7.1 días (mediana 7) y la distribución por sexo fue de 60 mujeres y 48 hombres (55 y $45 \%$, respectivamente).

Del total de las 108 TC efectuadas (pacientes con cuadro moderado o severo), 58 fueron anormales y 50 normales (53 y 48\%, respectivamente). De las 58 anormales, llamó la atención que tres pacientes tuvieron como resultados definitivos negatividad de la rt-PCR, incluso uno de ellos resultó con la PCR positiva para virus de influenza-B.

Llama la atención que se encontraron 19 estudios de TC con hallazgos altamente sugestivos de la enfermedad por COVID-19 y la prueba de PCR fue negativa; no obstante, en una segunda prueba se positivizaron en seis casos.

En la Tabla 1, se describen los hallazgos más comunes que fueron identificados en los pacientes con tomografías computarizadas, y su correlación con lo reportado en la literatura, particularmente por autores chinos, ${ }^{4-7}$ así como por el artículo de Kanne. ${ }^{8}$
Definiciones de los signos tomográficos ${ }^{9}$

A continuación, se presentan los principales hallazgos en estudios de TC:

- Opacidades en "vidrio despulido" (ground-glass). Se refiere a zonas de incremento en la atenuación (de aspecto brumoso) sin oscurecimiento de las estructuras subyacentes (vasos y bronquios).

- Consolidación. Es una zona de aumento en la atenuación con ocupación del espacio aéreo (con broncograma aéreo).

- Patrón en "empedrado" (crazy-paving). Se distingue por la combinación de leve engrosamiento de septos interlobulares sobre áreas de vidrio despulido.

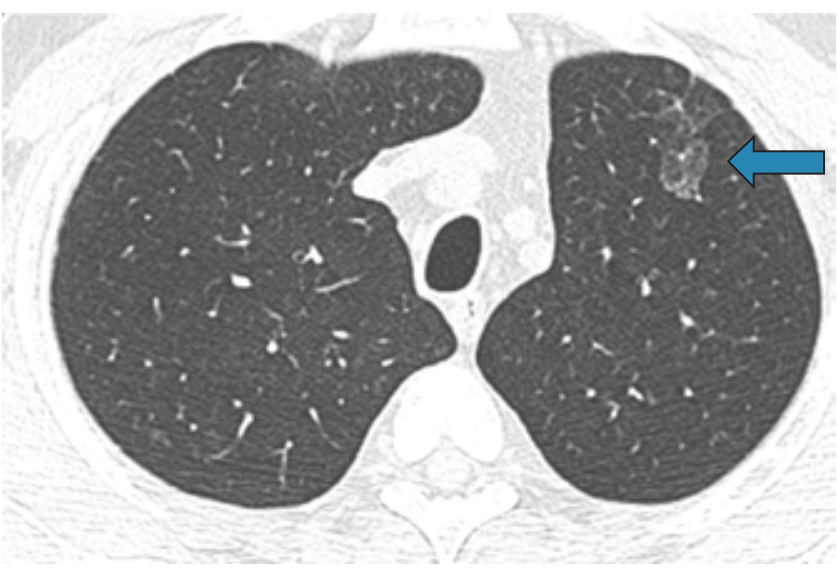

Figura 2: "Vidrio despulido" asimétrico. La flecha señala el territorio afectado (segmento 3).

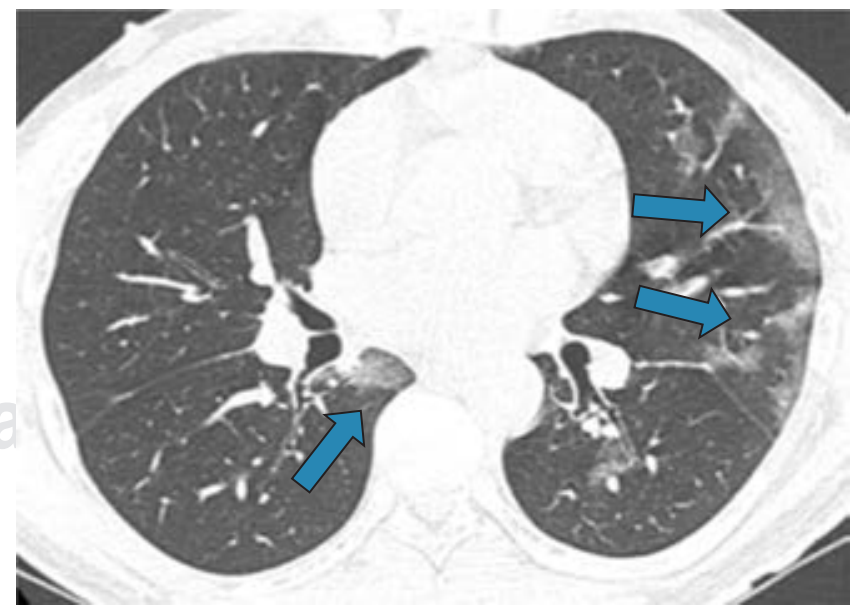

Figura 3: "Vidrio despulido" asimétrico bilateral. En el pulmón derecho en el segmento 6 , y en el izquierdo en los segmentos 5 y 8. 
- Opacidades lineales. Son áreas de mayor densidad, habitualmente periféricas, que se traducen en engrosamiento intersticial (septos).

- Cavitación. Es el espacio intraparenquimatoso que contiene gas y de grosor parietal variable. Implica una necrosis pulmonar con expulsión del contenido a través de la vía traqueobronquial.

- Nódulos no calcificados. Se trata de lesiones sólidas confluentes sin contenido cálcico.

- Derrame pleural. Es el acúmulo de líquido (exudado o trasudado) en espacio pleural.

- Adenopatías. Se refiere al incremento en número y en dimensiones de ganglios linfáticos contenidos en los distintos relevos del mediastino.

\section{DISCUSIÓN}

La enfermedad por COVID-19 es un problema de salud pública muy serio, ya que, si bien los coronavirus se describieron desde hace mucho tiempo, esta variedad es mucho más agresiva que las demás (incluyendo al SARS y al MERS). Este virus, en tan sólo cuatro meses de pandemia, ha hecho que prácticamente todos los investigadores del mundo estén volcando sus recursos y conocimientos para entender, predecir, tratar y evitar la infección. Diacrónicamente, desde el punto de vista de la medicina, dicho lapso es muy corto e inespecífico, y apenas estamos aprendiendo a entenderla. Aunque se le llamó neumonía por COVID-19, es necesario ir aceptando que, si bien muchos pacientes tienen manifestaciones que se originan por el daño a las vías aéreas (superiores e inferiores), muchos otros aparatos y sistemas también se afectan, y esto puede ser manifestaciones primarias y únicas de la enfermedad (aparato circulatorio, sistema nervioso, piel, entre otros).

Aunque los hallazgos en territorio pulmonar a través de la tomografía computarizada han sido muy socorridos e, inclusive, han sido propuestos como alternativa diagnóstica primaria (cuando no se cuenta con la prueba de rt-PCR), nuestra serie demuestra que hay pacientes cuyo cuadro clínico es sugestivo de la patología (y con antecedentes epidemiológicos) además de tener hallazgos sugerentes, pero que la prueba confirmatoria en el hisopado es negativa. Existen varias publicaciones en las cuales se explica de manera clara la razón (entre ello, se debe a las malas técnica de hisopado o a una carga viral baja al momento del estudio). Otro aspecto es que las manifestaciones por imagen del COVID-19 no son patognomónicas, más bien otras infecciones virales pueden provocarlas.

Figura 4:

Consolidación. Extensa zona de ocupación alveolar con formación de broncograma aéreo en territorio del lóbulo inferior izquierdo. Se muestran en planos axial y coronal.
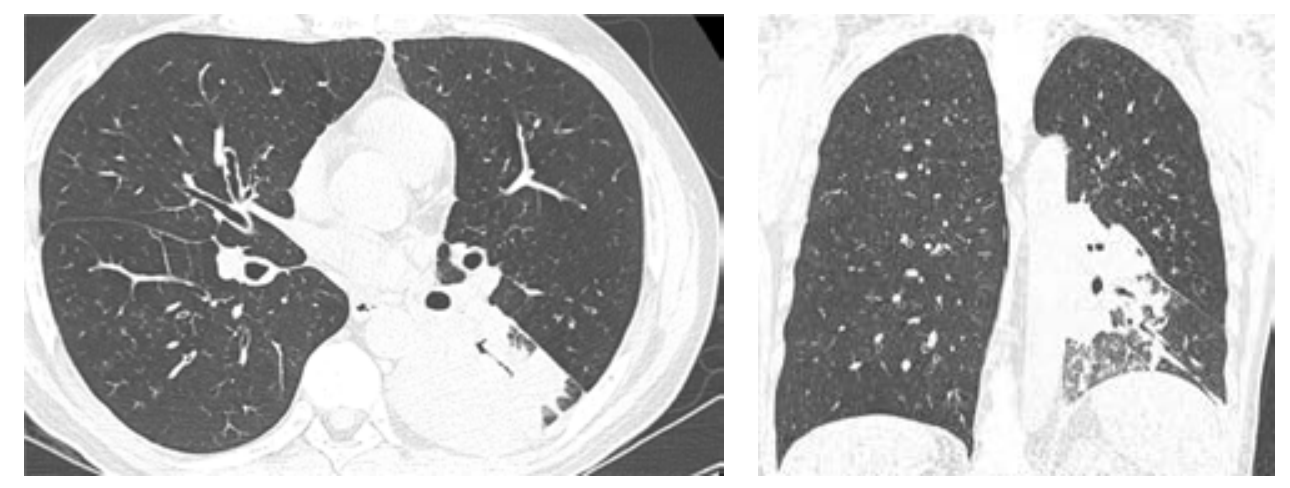
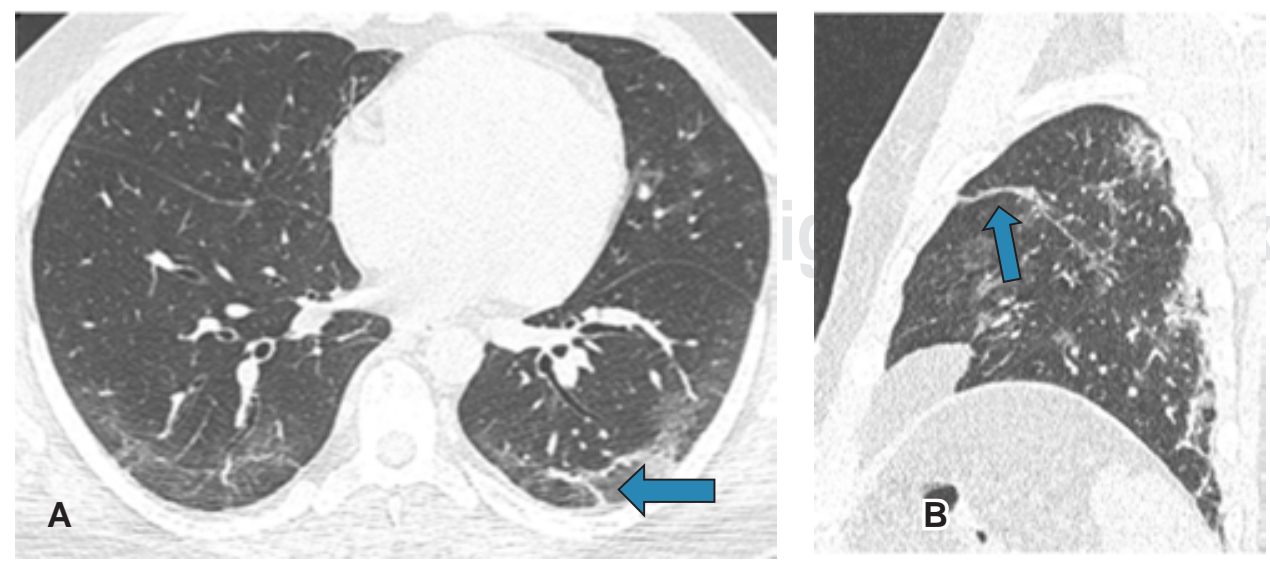

Figura 5:

(A y B) Opacidades lineales (flechas) de localización periférica en lóbulo inferior izquierdo en plano axial. (B) Reconstrucción sagital en lóbulo superior izquierdo. 


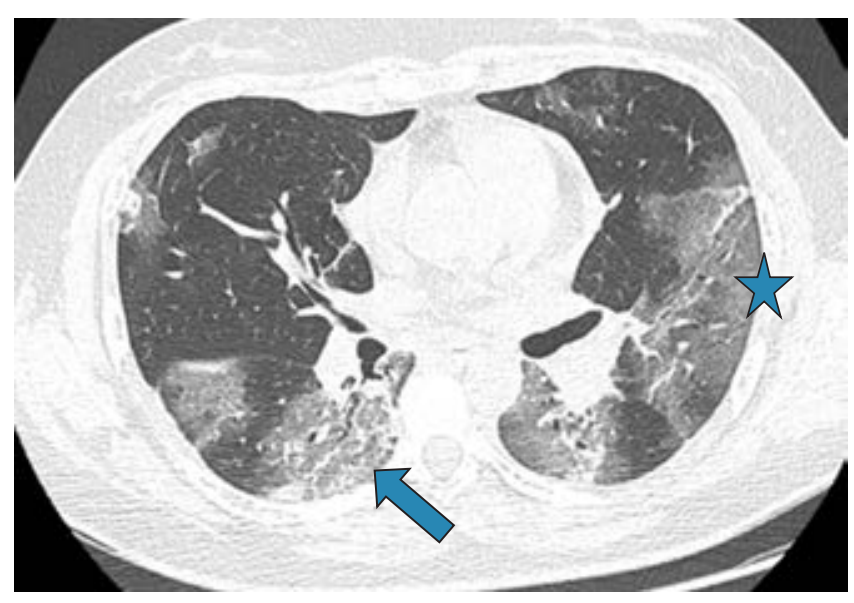

Figura 6: Patrón en "empedrado" (crazy-paving). La flecha muestra aspecto "en empedrado" asociado con "vidrio despulido". La estrella muestra "vidrio despulido" así como opacidades lineales.

También es prudente tratar de dividir al contagio del virus en una persona con que la persona se enferme, es decir, independientemente de la prueba de rt-PCR (limitada en tiempo de entrega de resultados), una tomografía computarizada normal no excluye la infección, pero sí la enfermedad por lo menos en lo referente al territorio de las vías aéreas inferiores.

Es prudente también señalar que, en fechas recientes, se han propuesto varias clasificaciones de acuerdo con los hallazgos por $\mathrm{TC},{ }^{11,12}$ sin embargo, parece muy prematuro establecer este tipo de clasificaciones cuando no tienen ningún factor pronóstico, sólo diagnóstico. En nuestra serie, los hallazgos tomográficos no difieren mayormente con los ya publicados con antelación básicamente en revistas especializadas de literatura radiológica.

\section{CONCLUSIONES}

La enfermedad por SARS-CoV-2, también llamada COVID-19, es una infección de origen viral que ha puesto a los sistemas de salud del mundo en vilo. Su aparición súbita, así como su gran contagiosidad, la convirtió rápidamente en una pandemia. En la actualidad, ya hay varios millones de casos en el mundo, y si bien su letalidad es más baja que otros virus de la familia de los coronavirus, el impacto es y será muy importante.

Es necesario que consideremos que las manifestaciones clínicas originalmente asentadas en las vías respiratorias se han ido ampliando de manera significativa a otras áreas de la economía del paciente.
La disponibilidad de pruebas diagnósticas, sus costos y el acceso también han sido un reto para los sistemas de salud. La radiología ha sido protagonista de primera línea, ya que las manifestaciones en la tomografía computarizada han sido muy sensibles pero no tan específicas; sin embargo, existe una inconsistencia entre la clínica, los resultados del laboratorio (rt-PCR) y la TC.

Finalmente, queda mucho por saber, ya que ésta es una enfermedad nueva, de la cual, sin duda, debemos seguir aprendiendo y conociendo a profundidad.

\section{REFERENCIAS}

1. Lu H, Stratton CW, Tang YW. Outbreak of pneumonia of unknown etiology in Wuhan, China: the mystery and the miracle. J Med Virol. 2020; 92: 401-402.

2. Cheng VC, Lau SK, Woo PC, Yuen KY. Severe acute respiratory syndrome coronavirus as an agent of emerging and reemerging infection. Clin Microbiol Rev. 2007; 20: 660-964.

3. Ramadan N, Shaib H. Middle east respiratory syndrome coronavirus (MERS-CoV): a review. Germs. 2019; 9: 35-42.

4. Li Y, Xia L. Coranavirus disease 2019 (COVID-19): role of chest CT in diagnosis and management. AJR Am J Roentgenol. 2020: 1-7. doi: 10.2214/AJR.20.22954. [Epub ahead of print].

5. Zhou S, Wang Y, Zhu T, Xia L. CT features of coronavirus disease 2019 (COVID-19) pneumonia in 62 patients in Wuhan, China. AJR Am J Roentgenol. 2020: 1-8. doi: 10.2214/AJR.20.22975. [Epub ahead of print].

6. Cheng Z, Lu Y, Cao Q, Qin L, Pan Z, Yan F, Yang W. Clinical features and chest CT manifestation of coronavirus disease 2019 (COVID-2019) in a single-center study in Shanghai, China. AJR Am J Roentgenol. 2020: 1-6. doi: 10.2214/AJR.20.22959. [Epub ahead of print].

7. Han R, Huang L, Jiang H, Dong J, Peng H, Zhang D. Early clinical and CT manifestations of coronavirus disease 2019 (COVID-19) pneumonia. AJR Am J Roentgenol. 2020: 1-6. doi: 10.2214/ AJR.20.22961. [Epub ahead of print].

8. Kanne J. Chest CT findings in 2019 novel coronavirus (2019-nCoV) infections from Wuhan, China: key points for the radiologist. Radiology. 2020; 295 (1): 16-17.

9. Hansell DM, Bankier AA, McLoud T, Müller NL, Remy J. Fleischner society: glossary of term for thoracic imaging. Radiology. 2008; 246 (3): 697-722.

10. Bai HX, Hsieh B, Xiong Z, Halsey K, Choi JW, Tran TML et al. Performance of radiologist in differentiating COVID-19 from viral pneumonia on chest CT. Radiology. 2020: 200823. doi: 10.1148/ radiol.2020200823. [Epub ahead of print].

11. Simpson S, Kay FU, Abbara S, Bhalla S, Chung JH, Chung M et al. Radiological Society of North America Expert Consensus Statement on Reporting Chest CT Findings Related to COVID-19. Endorsed by the Society of Thoracic Radiology, the American College of Radiology, and RSNA. J Thorac Imaging. 2020. doi: 10.1097/ RTI.0000000000000524. [Epub ahead of print].

12. Prokop M, van Everdingen W, van Rees Vellinga T, Quarles van Ufford J, Stöger L, Beenen L et al. CO-RADS - A categorical CT assessment scheme for patients with suspected COVID-19: definition and evaluation. Radiology. 2020: 201473. doi: 10.1148/ radiol.2020201473. [Epub ahead of print]. 